преподаватель кафедры уголовного процесса Кубанского государственного университета

\section{НАПУТСТВЕННОЕ СЛОВО ПРЕДСЕДАТЕЛЬСТВУЮЩЕГО В СУДЕ С УЧАСТИЕМ ПРИСЯЖНЫХ ЗАСЕДАТЕЛЕЙ}

Аннотация:

В статье раскрываются проблемы содержания и структуры напутственного слова председательствующего в суде с участием присяжных заседателей. Оцениваются отдельные аспекты данного процессуального действия с точки зрения объективности и непредвзятости. Обосновывается мнение, что напутственное слово председательствующего является одним из ключевых моментов его процессуального статуса с возможностью воздействия на конечный результат судебного процесса. На основе анализа правовых положений и мнений ученых автор выделяет ряд проблем напутственного слова председательствующего и приходит к выводу о необходимости законодательного закрепления гарантий, обеспечивающих объективность напутственного слова и исключающих нежелательное воздействие на коллегию присяжных заседателей. В заключение формулируются предложения по внесению изменений в статью 340 Уголовно-процессуального кодекса Российской Федерации.

Ключевые слова:

суд присяжных, производство в суде присяжных, напутственное слово председательствующего, присяжные заседатели, председательствующий судья.
Lecturer, Criminal Procedure Department, Kuban State University

THE DIRECTION OF A PRESIDING JUDGE IN A JURY TRIAL

\begin{abstract}
Summary
The study reveals the problematic content and struc ture of the direction of a presiding judge in a jury trial. The certain aspects of this procedure are evaluated in terms of objectivity and impartiality. The research proves that the direction of a presiding judge is one of the key points of his procedural status providing the ability to influence the outcome of the trial. Based on the analysis of legal provisions and views of scientists, the author highlights a number of concerns in regard to directions given by a presiding judge. The researcher concludes that it is necessary to enshrine guarantees in law to ensure that the direction is objective and prevent undesirable effects on the jury. In conclusion, it is proposed to amend Article $\mathbf{3 4 0}$ of the Criminal Procedure Code of the Russian Federation.
\end{abstract}

Keywords: jury trial, jury procedure, direction of a presiding judge, jury, presiding judge.

Суд присяжных в современном российском обществе занимает одно из центральных мест в осуществлении правосудия с точки зрения защиты прав и свобод граждан. Именно суд присяжных в полной мере может обеспечить честный и беспристрастный судебный процесс, а также гарантировать принятие независимого и объективного решения.

При этом нельзя не отметить, что работа суда присяжных связана со множеством процедурных трудностей, процессуальных ограничений и обязанностей для участников судопроизводства: начиная с формирования коллегии присяжных заседателей и заканчивая вынесением итогового решения. Это накладывает определенные ограничения на участников и предъявляет к ним повышенные требования в судебном разбирательстве, ведь они работают с юридически неподготовленными людьми.

Основные задачи по организации работы присяжных заседателей выполняет председательствующий судья. На него возложена ответственность за весь процесс, с одной стороны, и за человеческие судьбы - с другой. Здесь следует отметить, что мы говорим о судьбах не только подсудимых и потерпевших, но и самих присяжных, так как им может быть крайне трудно психологически принимать решения о виновности или невиновности лица. В суде, проводимом в данной форме, сталкиваются интересы множества участников, и от решений и действий председательствующего судьи в значительной степени зависят судьбы их всех.

Согласно положениям гл. 42 Уголовно-процессуального кодекса Российской Федерации (УПК РФ), председательствующий судья в ходе судебного разбирательства в суде с участием присяжных заседателей обладает обширным инструментарием по ведению процесса. Напутственное слово председательствующего является одним из ключевых моментов его процессуального статуса с воздействием на конечный итог судоговорения. Это действие, по сути, является итоговым для присяжных заседателей, которые после его завершения должны удалиться в совещательную комнату для вынесения вердикта. 
Н.В. Григорьева отмечает, что напутственное слово председательствующего завершает процесс восприятия присяжными доказательств и аргументов сторон и в необходимой степени осведомляет о юридических положениях их деятельности [1, с. 161]. С.А. Насонов считает, что напутственное слово является самым мощным средством воздействия на присяжных заседателей, «ultima ratio - самый действенный аргумент, склоняющий чашу весов правосудия в ту или другую сторону» [2, с. 860].

Мы согласны с такой оценкой процессуальной значимости напутственного слова, и в связи с этим важно, чтобы судья при его произнесении придерживался принципов объективности и состязательности и не делал уклона в пользу одной из сторон. Внести в него изменения или еще как-то исправить допущенные нарушения после удаления присяжных в совещательную комнату для постановления приговора невозможно.

На практике часто бывает, что судьи в своем напутственном слове допускают нарушения норм уголовно-процессуального закона, что впоследствии может стать основанием для отмены приговора и возвращения дела на новое рассмотрение. Так, судебная коллегия по уголовным делам Верховного суда Российской Федерации установила, что председательствующим судьей в напутственном слове были сообщены сведения, направленные на установление допустимости доказательств [3]. По другому уголовному делу осужденный Д.А. Семенцов приводит в обоснование жалобы сведения о том, что председательствующий исказил показания свидетеля защит; в напутственном слове были приведены данные показаний подозреваемого А.В. Трубицина о преступлении в отношении М., однако Д.А. Семенцов в этом преступлении не обвинялся; адвокат И.Ю. Зорина указывает на нарушения правил судебной практики при произнесении напутственного слова председательствующим [4]. В апелляционной жалобе адвокат О.В. Евсейчик в интересах осужденного А.Э. Простякова сообщает, что председательствующий при произнесении напутственного слова не указал на доказательства защиты, чем нарушил принцип беспристрастности [5]. По аналогичным обстоятельствам был отменен приговор по другому уголовному делу. Судебная коллегия указала на то, что председательствующим судьей в напутственном слове были приведены только доказательства обвинения [6]. Данные обстоятельства пагубны для судебной системы, участвующих лиц и в определенной мере для экономики страны.

С.А. Насонов отмечает, что именно критика напутственного слова председательствующего судьи является «...почти обязательным элементом большинства кассационных жалоб и представлений, подаваемых на приговор суда присяжных. Необъективность напутственного слова председательствующего судьи является частым основанием отмен как обвинительных, так и оправдательных приговоров, выносимых в российских судах присяжных» [7, с. 860].

Указанные обстоятельства могут только усугубиться после расширения подсудности суда присяжных летом 2018 г., когда данный правовой институт станет применяться на уровне районных судов. Это обусловлено большей загрузкой судей этого уровня, отсутствием опыта работы в данной форме судопроизводства и ее сложностью. Сейчас в судебном разбирательстве с участием присяжных заседателей рассматривается порядка 300 уголовных дел в год [8], после расширения подсудности их ожидается более 15 тысяч [9].

Т.М. Сыщикова и П.Н. Шабанов выделяют в качестве проблем напутственного слова председательствующего следующие:

- последовательность напоминания присяжным заседателям доказательств обвинения и защиты;

- изложение лишь доказательств стороны обвинения;

- проблема полноты изложения доказательств;

- корректировка позиций сторон в напутственном слове;

- разъяснение присяжным заседателям правил оценки доказательств с навязыванием роли «искателей истины»;

- несовпадение содержания напутственного слова, произнесенного председательствующим, с текстом в материалах дела [10].

Мы согласны с перечисленными проблемами и считаем, что к ним также можно отнести нерешенные вопросы о том, когда сторонам следует заявлять возражения на напутственное слово председательствующего и следует ли составлять напутственное слово в письменном виде и передавать присяжным заседателям в совещательную комнату.

Разрешение обозначенных проблем и предложение унифицированного подхода к напутственному слову позволит частично разгрузить председательствующего судью и снять ряд оснований для отмены приговора. Для этого необходимо рассмотреть каждый аспект напутственного слова в отдельности с последующим сведением выводов воедино в предложении законодателю.

Схожую позицию занимает С.А. Насонов, отмечающий, что «должны существовать весомые процессуальные гарантии, минимизирующие возможность неправомерного воздействия председательствующего судьи на присяжных заседателей посредством напутственного слова» [11, с. 103]. 
Напутственному слову председательствующего посвящена статья 340 УПК РФ, согласно которой: 1) перед удалением присяжных в совещательную комнату председательствующий обращается к ним с напутственным словом; 2) при обращении к присяжным председательствующему судье запрещается высказывать свое мнение относительно вопросов, поставленных перед ними; 3) председательствующий приводит содержание обвинения, сообщает содержание уголовного закона, предусматривающего ответственность за совершение деяния, в котором обвиняется подсудимый и т. д. (раскрывается примерная структура напутственного слова); 4) председательствующий завершает напутственное слово напоминанием присяжным о данной ими присяге; 5) что присяжные имеют право получить от судьи дополнительные разъяснения; 6) стороны имеют право заявить в судебном заседании возражения в связи с содержанием напутственного слова председательствующего.

При этом приведенная статья не дает четких «инструкций» относительно содержания и процедуры «донесения» напутственного слова до присяжных, оставляя некоторую вольность на усмотрение председательствующего судьи и, на наш взгляд, допуская некоторые упущения, о которых мы скажем далее.

Наиболее остро сейчас стоит вопрос содержания напутственного слова. Оно является своего рода краеугольным камнем послания председательствующего коллегии присяжных заседателей. От того, как и какую информацию председательствующий подает присяжным заседателям, во многом зависит расстановка акцентов при последующем разрешении вопросов. Например, если председательствующий будет чередовать каждое доказательство стороны защиты с опровергающими его доказательствами стороны обвинения, это окажет сильное воздействие на присяжных, сведет на нет усилия стороны защиты и нарушит принцип состязательности сторон. Это особенно актуально при соответствующей эмоциональной и интонационной окраске речи.

Также к обозначенной проблеме относится несовпадение содержания напутственного слова, произнесенного председательствующим, с текстом в материалах дела. Необходимо устранить возможность такого нарушения. Этого можно добиться путем закрепления в законе требования составлять напутственное слово в письменном виде и согласовывать его со сторонами. Отсюда вытекает решение еще одного вопроса, известного в практике и науке: когда следует заявлять возражения на напутственное слово. Существуют разные подходы.

Н.В. Григорьева полагает, что возражения на напутственное слово председательствующего судьи следует подавать после их удаления в совещательную комнату [12].

А.П. Шурыгин считает данную позицию ошибочной, отмечая, что возражения на напутственное слово председательствующего необходимо выслушивать в присутствии присяжных [13]. Аналогичную позицию занимает Е.П. Кудрявцева [14].

По нашему мнению, необходимо рассмотреть в корне новое решение обозначенных проблем напутственного слова председательствующего. Если напутственное слово разрабатывать при участии сторон по аналогии с вопросным листом, не будет необходимости в заявлении возражений в привычном нам виде. Представляется оправданной ситуация, при которой председательствующий судья готовит проект напутственного слова и передает его сторонам, те в свою очередь изучают его и заявляют замечания и предложения в письменном виде (если такие будут). Судья в обязательном порядке реагирует на заявленные замечания и предложения в письменном виде с передачей данных решений сторонам. После этого напутственное слово окончательно редактируется председательствующим и оглашается перед присяжными. Также, по нашему мнению, напутственное слово в письменном виде должно передаваться в совещательную комнату присяжным.

Это предложение обусловлено тем, что напутственное слово может быть довольно объемным и воспринять его на слух полностью невозможно. В нем содержится информация обо всех ключевых моментах судебного следствия и разъяснения закона. Т. Моэт отмечает, что напутственное слово в США обычно произносится в течение 10-15 минут, но в сложных делах его произнесение может длиться гораздо дольше $[15$, р. 9]. По нашему мнению, возможность пользоваться текстом напутственного слова положительно скажется на работе присяжных, что поможет всестороннему и объективному разрешению дела. С.А. Коломенская отмечает что «во многих американских судах в настоящее время позволяется или даже требуется, чтобы судьи вручали присяжным письменный экземпляр напутственного слова. Это облегчает восприятие присяжными правовых вопросов, содержащихся в напутствии» [16, с. 62].

В связи с изложенным выше предлагаем изложить ст. 340 УПК РФ в следующей редакции: «1. Судья с учетом результатов судебного следствия, прений сторон формулирует в письменном виде напутственное слово и передает его сторонам.

2. Стороны вправе подать свои замечания по содержанию и формулировке напутственного слова и внести предложения и замечания по его содержанию. При этом судья не вправе 
отказать сторонам в подаче данных заявлений. Каждое заявление сторон касательно напутственного слова председательствующего должно быть разрешено (удовлетворено или отклонено) с последующим приобщением к материалам дела.

3. С учетом замечаний и предложений сторон судья в совещательной комнате окончательно формулирует напутственное слово, подлежащее оглашению перед присяжными заседателями, которое подписывается им.

4. На время обсуждения и формулирования напутственного слова присяжные заседатели удаляются из зала судебного заседания.

5. Перед удалением коллегии присяжных заседателей в совещательную комнату для вынесения вердикта председательствующий обращается к присяжным заседателям с напутственным словом, которое после передается старшине присяжных.

6. Аналогично ч. 2 действующей редакции сm. 340 УПК РФ.

7. В напутствующем слове председательствующий:

1) аналогично п. 1 ч. 3 действующей редакции сm. 340 УПК РФ;

2) в доступной форме сообщает содержание уголовного закона, предусматривающего ответственность за совершение деяния, в котором обвиняется подсудимый;

3) напоминает об исследованных в суде доказательствах, как уличающих подсудимого, так и оправдывающих его, в той последовательности, в какой они исследовались в рамках судебного следствия, в объеме, достаточном для понимания, не выражая при этом своего отношения к этим доказательствам и не делая выводов из них;

п. 4-7 - аналогично п. 4-7 ч. 3 действующей редакции ст. 340 УПК РФ.

8. Аналогично ч. 4 действующей редакции ст. 340 УПК РФ.

9. Присяжные заседатели, выслушав председательствующего и ознакомившись с поставленными перед ними вопросами, вправе получить от него дополнительные разъяснения.

10. Если сторонами не были своевременно заявлены возражения на напутственное слово, они не вправе ссылаться в дальнейшем на содержание напутственного слова председательствующего судьи как основание для пересмотра этого дела вышестоящим судьей».

\section{Ссылки:}

1. Григорьева Н.В. Напутственное слово председательствующего // Состязательное правосудие : тр. науч.-практ. лабораторий. Вып. 1. Ч. 1. М., 1996. С. 161-180.

2. Насонов С.А. Напутственное слово председательствующего судьи в исторических моделях производства в суде присяжных // Lex Russica. 2011. T. LXX, № 5. C. 859-872.

3. Апелляционное определение Верховного суда РФ от 4 окт. 2016 г. № 18-АПУ16-19СП [Электронный ресурс] // Верховный суд Российской Федерации. URL: http://www.vsrf.ru/stor_pdf.php?id=1480142 (дата обращения: 11.05.2018).

4. Апелляционное определение Верховного суда РФ от 20 июля 2016 г. № 56-АПУ16-16СП [Электронный ресурс] // Законы, кодексы и нормативно-правовые акты Российской Федерации. URL: http://legalacts.ru/sud/apelliatsionnoeopredelenie-verkhovnogo-suda-rf-ot-20072016-n-56-apu16-16sp/ (дата обращения: 11.05.2018).

5. Апелляционное определение Верховного суда РФ от 11 янв. 2017 г. № 47-АПУ16-10СП [Электронный ресурс] // Верховный суд Российской Федерации. URL: http://www.vsrf.ru/stor_pdf.php?id=1508722 (дата обращения: 11.05.2018).

6. Кассационное определение Верховного суда РФ от 7 июня 2006 г. № 73-О05-50СП [Электронный ресурс]. Доступ из справ.-правовой системы «Гарант».

7. Насонов С.А. Напутственное слово председательствующего судьи ... С. 860

8. См.: Основные статистические показатели деятельности судов общей юрисдикции за 2015 г. [Электронный ресурс] // Официальный сайт Судебного департамента при Верховном суде Российской Федерации. URL: http://cdep.ru/index.php?id=79\&item=3383 (дата обращения: 11.05.2018) ; Основные статистические показатели деятельности судов общей юрисдикции за 2016 г. [Электронный ресурc] // Там же. URL: http://cdep.ru/index.php?id=79 (дата обращения: 11.05.2018) ; Основные статистические показатели деятельности судов общей юрисдикции за 2017 г. [Электронный ресурс] // Там же. URL: http://cdep.ru/index.php?id=79 (дата обращения: 11.05.2018).

9. Куликов В. Рассудят шестеро [Электронный ресурс] // Российская газета. 2016. № 7007. URL: https://rg.ru/2016/06/27/zakon-rasshiril-primenenie-sudov-prisiazhnyh.html (дата обращения: 11.05.2018).

10. Сыщикова Т.М., Шабанов П.Н. Напутственное слово председательствующего // Юридические записки. 2012. № 2 (25). C. 175-181.

11. Насонов С.А. Напутственное слово председательствующего в суде присяжных: значение, свойства и требования // Вопросы современной юриспруденции. 2013. № 27. С. 101-108.

12. Григорьева Н.В. Указ. соч.

13. Шурыгин А.П. Защита в судопроизводстве с участием присяжных заседателей (вопросы кассационной практики) // Защитник в суде присяжных. М., 1997. С. 104-121.

14. Рассмотрение дел судом присяжных : науч.-практ. пособие / отв. ред. В.М. Лебедев. М., 1998. С. 280-281.

15. Mauet T.A. Trial Techniques. $6^{\text {th }}$ ed. N. Y., 2002. 598 p.

16. Коломенская С.А. Напутственное слово председательствующего в уголовном процессе США // Российский судья. 2016. № 8. C. 61-64. 


\section{References:}

Grigoryeva, NV 1996, 'The direction of a presiding judge', Sostyazatel'noye pravosudiye: tr. nauch.-prakt. laboratoriy, Iss. 1, Part 1, Moscow, pp. 161-180, (in Russian).

Kolomenskaya, SA 2016, 'The direction of a presiding judge in the US criminal procedure', Rossiyskiy sud'ya, No. 8, pp. 6164, (in Russian).

Kulikov, V 2016, 'Six of them will judge', Rossiyskaya gazeta, No. 7007, viewed 11 May 2018, <https://rg.ru/2016/06/27/zakon-rasshiril-primenenie-sudov-prisiazhnyh.html>, (in Russian).

Lebedev, VM (ed.) 1998, Case-handling by a jury trial, manual, Moscow, pp. 280-281, (in Russian).

Mauet, TA 2002, Trial Techniques, $6^{\text {th }}$ ed., New York, 598 p.

Nasonov, SA 2011, 'The direction of a presiding judge in the historical models of the jury procedure', Lex Russica, Vol. LXX, No. 5, pp. 859-872, (in Russian)

Nasonov, SA 2013, 'A direction of the presiding judge in the jury procedure: significance, properties and requirements', Voprosy sovremennoy yurisprudentsii, No. 27, pp. 101-108, (in Russian).

Shurygin, AP 1997, 'Defense in the jury procedure (issues of cassation practice)', Zashchitnik v sude prisyazhnykh, Moscow, pp. 104-121, (in Russian).

Syschikova, TM \& Shabanov, PN 2012, 'The direction of a presiding judge', Yuridicheskiye zapiski, No. 2 (25), pp. 175-181, (in Russian).

'The appellate decision of the Supreme Court of the Russian Federation No. 18-АПУ16-19CП as of October 04, 2016' 2018, Verkhovnyy sud Rossiyskoy Federatsii, viewed 11 May 2018, <http://www.vsrf.ru/stor_pdf.php?id=1480142>, (in Russian).

'The appellate decision of the Supreme Court of the Russian Federation No. 47-AПУ16-10CП as of January 11, 2017' 2018, Verkhovnyy sud Rossiyskoy Federatsii, viewed 11 May 2018, <http://www.vsrf.ru/stor pdf.php?id=1508722>, (in Russian).

'The appellate decision of the Supreme Court of the Russian Federation No. 56-AПУ16-16CП as of July 20, 2016' 2018, Zakony, kodeksy i normativno-pravovyye akty Rossiyskoy Federatsii, viewed 11 May 2018, <http://legalacts.ru/sud/apelliatsionnoe-opredelenie-verkhovnogo-suda-rf-ot-20072016-n-56-apu16-16sp/>, (in Russian).

'The basic statistics of the general courts activities for 2015' 2018, Ofitsial'nyy sayt Sudebnogo departamenta pri Verkhovnom sude Rossiyskoy Federatsii, viewed 11 May 2018, <http://cdep.ru/index.php?id=79\&item=3383>, (in Russian).

'The basic statistics of the general courts activities for 2016' 2018, Ofitsial'nyy sayt Sudebnogo departamenta pri Verkhovnom sude Rossiyskoy Federatsii, viewed 11 May 2018, <http://cdep.ru/index.php?id=79>, (in Russian)

'The basic statistics of the general courts activities for 2017' 2018, Ofitsial'nyy sayt Sudebnogo departamenta pri Verkhovnom sude Rossiyskoy Federatsii, viewed 11 May 2018, <http://cdep.ru/index.php?id=79>, (in Russian) 